\title{
The radiosensitization of melanoma cells by gold nanorods irradiated with MV X-ray
}

Wencai Xu ${ }^{1}$,Teng Luo ${ }^{2}$, Bo Pang ${ }^{4}$, Ping $\mathrm{Li}^{1}$, Chuanqing Zhou ${ }^{2}$, Peng Huang ${ }^{3}$, Chunlei Zhang ${ }^{3}$, Qiushi Ren", Wenbin Hu ${ }^{5 *}, S^{*}$. Fu ${ }^{1 *}$

${ }^{1}$ Department of Radiation Oncology, Shanghai Sixth People's Hospital, Shanghai Jiao Tong University, Shanghai 200030, China

${ }^{2}$ School of Biomedical Engineering, Shanghai Jiao Tong University, Shanghai 200240, China

${ }^{3}$ National Key Laboratory of Nano/Micro Fabrication Technology, Key Laboratory for Thin Film and Microfabrication of Ministry of Education, Institute of Micro-Nano Science and Technology, Shanghai Jiao Tong University, Shanghai 200240, China

${ }^{4}$ Department of Biomedical Engineering, College of Engineering, Peking University, Beijing 100871, China

${ }^{5}$ State Key Laboratory of Metal Matrix Composites, Shanghai Jiao Tong University,Shanghai 200240, China

* Corresponding author: wbhu@263.net(Weibin Hu)

Tel/fax: $(+86) 021-3420-2981$

fushen1117@gmail.com(Shen Fu)

Tel/fax: (+86) 021-2405-8643

\section{Abstract}

Melanoma is known to be radioresistant and traditional treatments have been intractable, and therefore, novel approaches are required to improve therapeutic efficacy. Gold nanoparticles (GNPs) have been explored as radiosensitizers, while most of the research in the area has focused on the enhancement occurred in the kilovoltage $(\mathrm{kV})$ range. The present study investigated the possible application and biological mechanism of gold nanorods (GNRs) for sensitization at clinically relevant MV X-ray energies. A375 melanoma cells were treated by gold nanorods (GNRs) with or without irradiation. The anti-proliferative impacts of the treatments were measured by MTT assay. The cellular uptake and intracellular localization were analyzed by transmission electron microscopy. Radiosensitizing effects were determined by a colony formation assay. Apoptosis and cell cycle data were measured by flow cytometry. DNA damage was estimated by $\gamma$-H2AX expression measured with immunofluorescent staining.

Results showed that the addition of GNRs enhanced the radiosensitivity of A375 cells with a dose-modifying factor (DMFSF2) of 1.14, increasing more radiation-induced DNA double-strand breaks and apoptosis. DNA flow cytometric analysis indicated that GNRs plus irradiation significantly induced G2/M phase arrest in A375 cells.

In Conclusions: GNRs could sensitize melanoma A375 cells to $6 \mathrm{MV}$ X-ray irradiation, and this was mainly through increasing the DNA doublestrand breaks, in addition to the induction of a higher proportion of cells within the G2/M phase. The interaction of GNRs and high energy commonly used in the clinic may provides another rational for the potential application of GNRs in the treatment of cancer..

Keywords: Melanoma cells, Gold nanoparticles, Irradiation

Citation: W. Xu, et al. The radiosensitization of melanoma cells by gold nanorods irradiated with MV X-ray . Nano Biomed. Eng. 2012, 4(1), 6-11 DOI: $10.5101 /$ nbe.v4i1.p6-11.

\section{Introduction}

The incidence of melanoma is increasing worldwide with an estimated age-standardized incidence rate (World 2000 population) of 40.2 cases per 100,000 population in 2008 [1]. Although surgery remains the primary treatment for patients with localized melanoma, available data indicate that there is a need for improved local-regional control in situations where complete surgical resection may be difficult or when high-risk features are noted pathologically, therefore, radiation therapy is one of the commonly utilized treatments for melanoma cancer [2], but malenoma cells are well known to be resistant to radiation [3, 4], and delivering a curative dose of radiation to tumor tissues while sparing normal tissues is still a great challenge in radiation therapy. Therefore, any new strategies that overcome the relative radioresistance of melanoma tumors could prove to be useful and beneficial to the patients.

Nanotechnology is an emerging technique for improved cellular targeting and radio-sensitization. Nanoparticles (NPs) are widely used to treat cancer $[5,6]$. Since nanoparticles are definition smaller than a typical cutoff size of the pores (e.g., up to $400 \mathrm{~nm}$ ) in the tumour vasculature [7], so they can take full advantage of the so-called 'leaky' vasculature of tumours [8]. Thus, nanoparticles may have a better chance of 
penetrating into the tumour interstitium. However, most studies have focused on low-energy radiation because high atomic number $(Z)$ materials, which preferentially absorb kilovoltage $x$-rays, the effect of a defined dosage is increased when a high- $Z$ material is in the targeted zone through a photoelectric effect $[9,10]$, of which the enhancement is proportional to the amount of the high- $Z$ material. Although $\mathrm{kV}$ energies like brachytherapy are still used in treatment of some cancer patients, megavoltage $\mathrm{x}$-rays are more commonly used in the clinic, particularly for deep-seated tumors. Therefore, it is necessary to study the radiosensitizing effect of $\mathrm{MV} \mathrm{x}$-rays since it cannot be attributed to high- $Z$ materials alone.

Other material nanopartilcles like iodine, gadolinium, etc, have been used to enhance the dose of radiation [11], but gold as nanoparticle constituent has shown more promise because gold nanoparticles have low cytotoxicity, robust stability, biocompatibility, and suitable physiochemical parameters [12]. The use of structurally modified gold nanoparticles is less toxic to normal tissue during delivery, and at the molecular level, could traverse biologic barriers and preferentially accumulate in cancer cells [13-14].

The present study investigated the benefit of combing gold nanorods with MV irradiation to treat radioresistant melanoma cancer cells, as well as assessing some possible mechanisms for the radiosensitizing effects of GNRs.

\section{Materials and Methods}

\section{Preparation of gold nanorods}

The GNRs were synthesized using the seed-mediated template-assisted protocol [15, 16], by reducing gold salt in the presence of surfactant directed synthesis. First, $20 \mathrm{~mL}$ aliquot of GNRs stock solution (Sinopharm Chemical Reagent Co., Shanghai, China) was centrifuged and redispersed in $20 \mathrm{~mL}$ deionized water (Millipore, Shanghai, China). Then, $1.1 \mathrm{~mL}$ of the TEOS ethanol solution (10 mM) (J \& K Chemical Ltd , Shanghai, China) was added to the $20 \mathrm{~mL}$ of aqueous GNRs ( $\mathrm{pH}$ adjusted to $10 \sim 11$ by $\mathrm{NH}_{4} \mathrm{OH}$ ). After vigorous stirring for $10 \mathrm{~h}$ at room temperature, an approximately $31 \mathrm{~nm}$ thick silica layer formed on the surface of the GNRs through hydrolysis and condensation of TEOS [17]. The silica-coated nanoparticles were isolated by centrifugation, washed with deionized water and ethanol several times, and then dispersed in DMEM medium (Hyclone, Carlsbad, CA, USA) and stored at $4^{\circ} \mathrm{C}$ for later cell experiments.

\section{Cell lines and Culture}

The human melanoma A375 cells were purchased from the Shanghai Institute of Cell Biology \& Chinese Academy of Sciences (Shanghai, China) and grown in DMEM medium containing 10\% heated-inactivated fetal bovine serum (Hyclone, USA). Cells were incubated at $37{ }^{\circ} \mathrm{C}$ in a humidified atmosphere with $50 \mathrm{ml} \mathrm{L}^{-1} \mathrm{CO}_{2}$.

\section{TEM analysis of cells with internalized Gold nanorods}

A375 cells incubated with GNRs were washed three times with PBS and fixed with $2.5 \%$ glutaraldehyde for 6 hours. The cells were then postfixed in $1 \%$ osmium teroxide for 2 hours, dehydrated in ethanol and embedded in agar resin. Thin section of $60-70 \mathrm{~nm}$ were collected on copper grids and stained with methanol and lead citrate. The grids were visualized using transmission electron microscopy (Philips CM120).

\section{Cellular proliferation assay}

Exponentially growthing cells were incubated with different concentrations of GNRs varying lengths of time. Then, $15 \mu \mathrm{L}$ of MTT solution ( $5 \mathrm{mg} \mathrm{mL}^{-1}$ ) (Sigma-Aldrich, USA) was added into each well for $4 \mathrm{~h}$ of incubation. The reaction was stopped by removal of MTT, and $100 \mu \mathrm{l}$ dimethylsulfoxide (DMSO) (Sigma-Aldrich, USA) was added into each well in order to dissolve the formazan crystals, and the plates were read at enzyme-labeling analyzer. All measurements were done in triplicate.

\section{Irradiation}

Cells in a monolayer were irradiated at room temperature using 6MV x-rays from linear accelerators

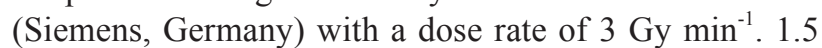
$\mathrm{cm}$ bolus were used as compensators.

\section{Clonogenic Assay}

A375 cells were seeded and grown in 6 well culture plates. 24 hours after incubation, GNRs $(50 \mu \mathrm{g} / \mathrm{ml}$ concentration solution) were introduced and kept for 1 hour before X-ray irradiation. After irradiation, the dishes were trypsinized, and different of detached cells were seeded and grown in 6 well culture plates. Cells were incubated for 2 weeks to form colonies. The colonies were stained with $0.4 \%$ crystal violet and the colonies containing $>50$ cells were counted for calculating the surviving fraction (SF). Values were expressed as the mean \pm standard deviation (SD). The survival curves were fitted to the Linear Quadratic (LQ) Model [S= exp($\alpha \mathrm{D}-\beta \mathrm{D} 2)]$ using least-squares regression in Prism 5.0 (GraphPad Software, CA). Dose modifying factor (DMF) values were calculated to quantify the radiosensitizing effect of the cells.

\section{Immunofluoresent assay for $\gamma-\mathrm{H} 2 \mathrm{~A} . \mathrm{X}$}

Cells were seeded on cover slides in a 6-well culture dish. After seeding the cells for 24 hours, GNRs $(50 \mu \mathrm{g}$ $\mathrm{mL}^{-1}$ ) were introduced and incubated for 1 hour before $\mathrm{X}$-ray irradiation. After irradiated, the cells were further incubated for 1 hour, then fixed in $1 \%$ paraformaldehyde for $30 \mathrm{~min}$ and permeabilized in $0.5 \%$ Triton X-100/PBS for $30 \mathrm{~min}$ at room temperature. Cover slips were washed three times with PBS, and the cells were blocked with $10 \%$ FBS for $30 \mathrm{~min}$ at room temperature. Subsequently the flourescein isothiocyanate ( FITC)-labeled mouse monoclonal antibody against $\gamma$-H2A.X (Millipore, USA) with 1:200 dilution in 10\% FBS was incubated for $1.5 \mathrm{~h}$ 
double-strand breaks (DSBs) induced by ionizing radiation. As shown in Fig. 4A, $\gamma-\mathrm{H} 2 \mathrm{~A}$.X foci could be clearly distinguished after irradiation(2Gy) of A375 cells. The average number of $\gamma-\mathrm{H} 2 \mathrm{~A}$.X foci per cell were counted in the micrographs and the results are presented in Fig. 4B. The average number of $\gamma-\mathrm{H} 2 \mathrm{~A}$.X foci per cell in cultures receiving the combined GNRs treatment was significantly greater compared with the irradiation alone $(\mathrm{p}<0.05)$.

\section{(FCM)}

A375 cells, (106 cells $\left.\mathrm{mL}^{-1}\right)$ fixed in $95 \%$ ethanol at $-20{ }^{\circ} \mathrm{C}$ for 24 hours, were washed with cold phosphatebuffered saline (PBS), re-suspended, and stained with propidium iodide (50 $\mathrm{g} \mathrm{mL}^{-1} \mathrm{PBS}$; Invitrogen, Shanghai, China) for $15 \mathrm{~min}$ at $4{ }^{\circ} \mathrm{C}$. Analysis was performed using a FACSCalibur flow cytometer (Becton-Dickinson, Franklin Lakes, NJ, USA). Cellular DNA content and cell cycle data were analyzed by FCM using multicycle system 2.0 software. For apoptosis assay, the cells were stained with Annexin-V-fluorescein isothiocyanate/ propidium iodide (Annexin-V-FITC/PI; Invitrogen) and measured by FCM. All tests were repeated three times.

\section{Statistical analysis}

The SPSS statistical software(13.0) was used for statistical analyses. The results were expressed as the means \pm standard deviation. The One-Way ANOVA was performed to compare the means between either two test groups with $\mathrm{p}$ value of $<0.05$ considered statistically significant.

\section{Result}

\section{Cellular toxicity and uptake of gold nanorods on A375 cells}

The GNRs coating with about $13 \mathrm{~nm}$ thick silica layer were used to reduce the biotoxicity derived from a large amount of the surfactant cetyltrimethylammonium bromide (CTAB) molecules during GNRs (GNRs, length: $44.44 \pm 4.7 \mathrm{~nm}$; width: $15.10 \pm 1.7 \mathrm{~nm})$ synthesis, which had a uniform silica shell (thickness $\approx 13 \mathrm{~nm}$ ), as shown in Fig. 1B. MTT assays showed that GNRs were biologically nontoxic within the concentration of $50 \mu \mathrm{g}$ $\mathrm{mL}^{-1}$ in 24 hours $(\mathrm{p}<0.05)$ (Fig. 2). A375 cells treated with GNRs $\left(50 \mu \mathrm{g} \mathrm{mL}^{-1}\right)$ for 1 hours, internalized GNRs into the cells by endocytosis (Fig. 1A).

\section{The radiosensitization of melanoma cells by gold nanorods}

As illustrated in Fig. 3, when cells were treat ed with GNRs $(50 \mu \mathrm{g} / \mathrm{ml})$, the cell survival fraction at 2 Gy dropped from $55.4 \%$ of control group to $48.7 \%$. Significant radiosensitization was observed at GNRs with the DMF (SF2) of 1.14, compared with the control group $(\mathrm{p}=0.012)$.

\section{Analysis of DNA double-strand break}

$\gamma$-H2A.X foci was assessed as indicator of DNA

\section{Enhanced radiation-induced apoptosis by gold nanorods in melanoma cells}

The apoptotic percentage of the A375 cells after variable treatments were shown in Fig. 5. The cell incorporation of GNRs did not significantly increase the amount of cell apoptosis compared to control values. Radiation alone (6MV X-rays at a dose of 4 Gy) or combined with GNRs, significantly enhanced apoptosis (4.97 $\pm 0.83 \%$ and $7.67 \pm 0.31 \%$, respectively), compare to control values $(2.23 \pm 0.42 \%)(\mathrm{p}<0.05)$.

\section{The enhancement of radiation-induced G2 arrest by gold nonrods}

GNRs $\left(50 \mu \mathrm{g} \mathrm{mL}^{-1}\right)$ treating A375 cells for 1 hour caused cells to accumulate in the radiosensitive $\mathrm{G}_{2} / \mathrm{M}$ phase of the cell cycle, when compared with the control group. In our study, $25.84 \pm 0.49 \%$ of control cells were in the $\mathrm{G}_{2} / \mathrm{M}$ phase, while GNRs or radiation alone (6MV $\mathrm{X}$-rays with a dose of 4 Gy) significantly increased the fraction of cells in the $\mathrm{G}_{2} / \mathrm{M}$ phase to $35 \pm 2.65 \%$ and $40.9 \pm 0.35 \%$, respectively) $(\mathrm{p}<0.05)$. The cells treated with a combination of GNRs plus radiation further enhanced the cells arrest at $\mathrm{G}_{2} / \mathrm{M}$ phase $(46.5 \pm 1.2 \%)$. One-way ANOVA analysis has also shown that there were significant differences between the GNRs plus radiation group and both untreated and single treatment groups $(\mathrm{p}$ $<0.05)$.

\section{Discussion}

Nanotechnology has been intensively explored in the treatment of cancer. Nanotherapeutics are rapidly progressing and being implemented to solve some limitations of cancer radioresistances [19]. Melanoma cells are well known to be resistant to radiation; therefore, any new strategies like nanotechnology that overcome the relative radioresistance of melanoma tumors could prove to be useful and beneficial to many patients. In the present study, GNRs coated with $\mathrm{SiO}_{2}$ were used as sensitizer. Since cetyltrimethyl ammonium bromide (CTAB), which is a necessary structure-directing agent in the GNRs synthesis method, had severe cytoxicity and low stability when coated with CTAB, in order to solve the two problems, an additional coating material $\left(\mathrm{SiO}_{2}\right)$ has been deposited on the surface of CTAB. $\mathrm{SiO}_{2}$ has been reported to be stable and low toxicities, and is very suitable for using as a coating material for GNRs [20-21], and it also is very biocompatible, GNRs coating with silica can easily be covalently conjugated with antigen like peptides, antibody, etc [22-23], therefore, 

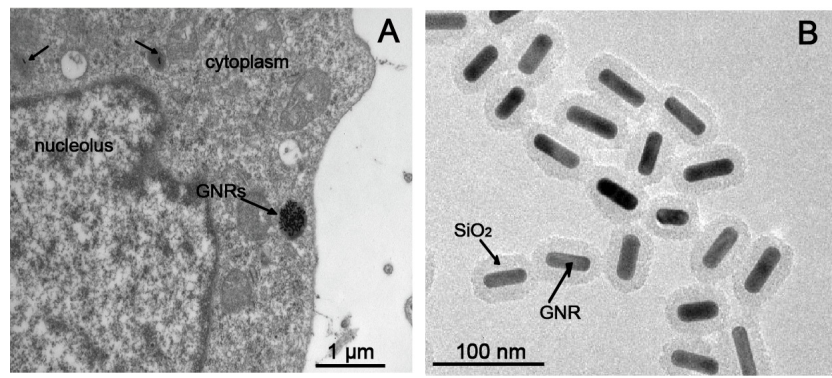

Fig. 1 Gold nanorods image and distribution in human melanoma A375 cells. A: TEM show A375 cells with internalized GNRs. B: transmission electron microscopy (TEM) image and structure of gold nanorods. (abbreviation: GNRs: gold nanorods)

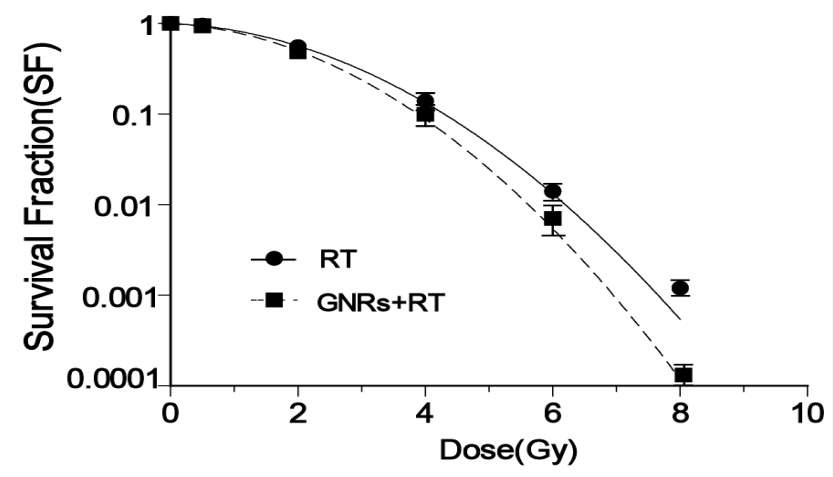

Fig. 3 The radiosensitiziting effect by GNRs . A375 cells were treated with GNRs $\left(50 \mu \mathrm{g} \mathrm{mL}^{-1}\right.$ for $\left.1 \mathrm{~h}\right)$ in combination of radiation with indicated doses, then cells were trypsinized, counted, seeded at different dilutions and incubated for colony formation for 14 days. Data points shown represent the mean survival fraction of three independent experiments, Bars, SD. (abbreviation: RT: radiotherapy).

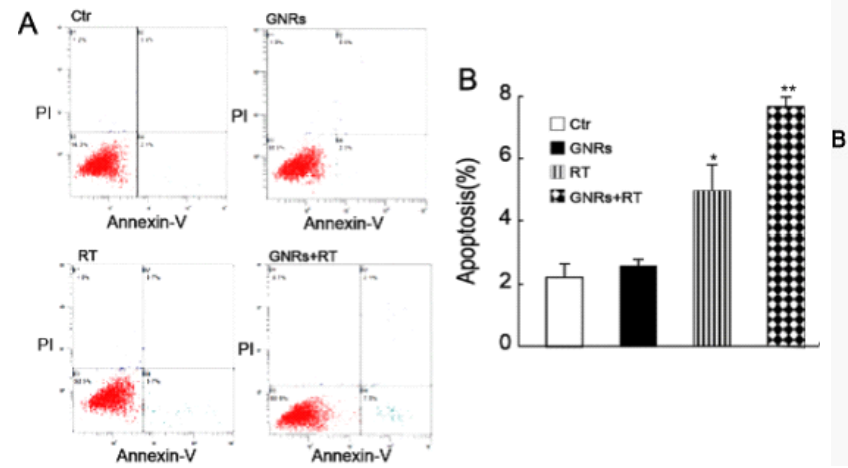

Fig. 5 Enhancement of radiation-induced apoptosis by GNRs. A375 cells were treated with GNRs $(50 \mu \mathrm{g} / \mathrm{ml})$ for $1 \mathrm{~h}$ prior to irradiation (6MV X-rays at a dose of $4 \mathrm{~Gy}$ ). The cells were cultured for 24 $\mathrm{h}$ then stained with Annexin V and propidium iodide (PI), and apoptosis analyzed by flow cytometry. A: Flow cytometry plots (Ctr- control; GNRs- gold nanorods without radiation; RT- radiation alone; GNRs+RT- GNRs plus radiation). B: Data from Fig. 5A were quantified shown (mean $\pm \mathrm{SD} ; \mathrm{n}=3$ experiments). ${ }^{*}, \mathrm{p}<0.05$ vs. control group; $* *, \mathrm{p}<0.05$ compared to other treated groups.

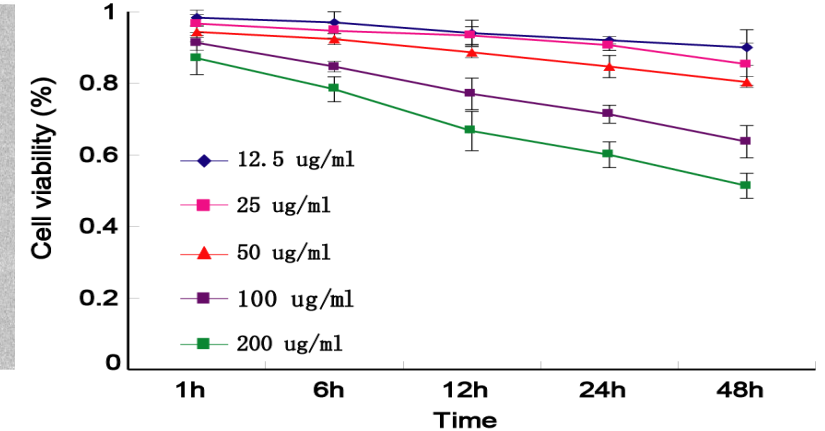

Fig. 2 Effects of GNRs on cell viability using MTT assay. A375 cells were treated with different concentrations of GNRs for variable times, and the A570 values following incubation with MTT stop solution were measured by an enzyme-labeling analyzer. Data were compared to the control group (assumed to be 1.0), and the relative viability of each experimental group was plotted.

A
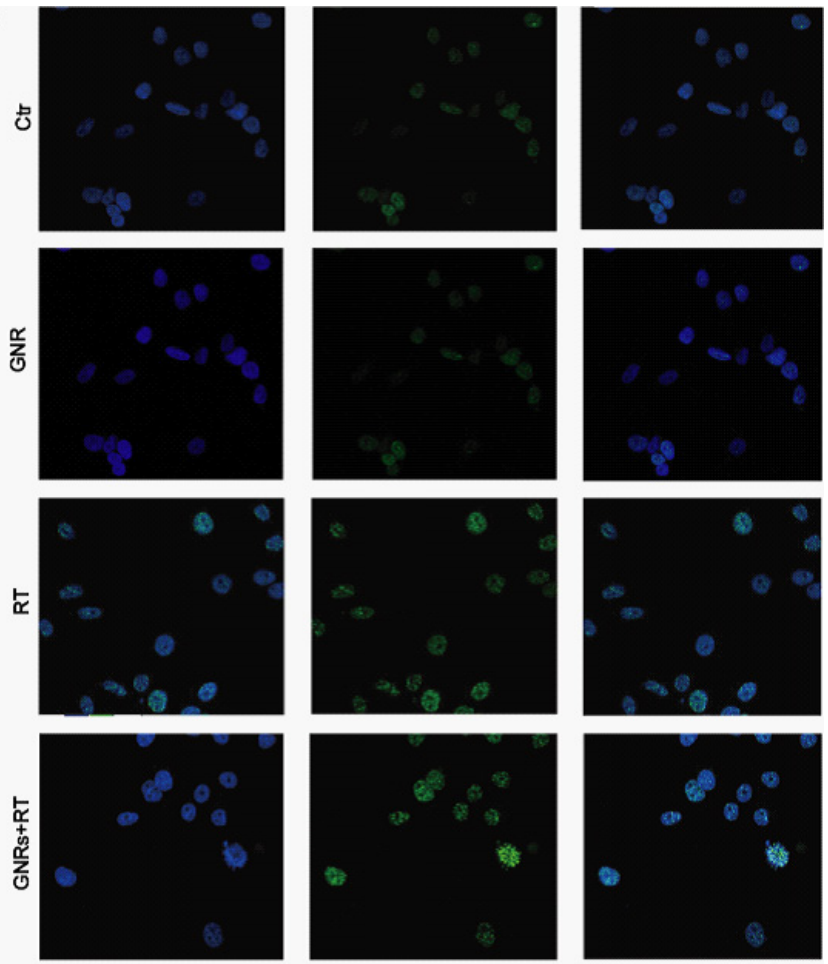

DAPI

$\mathrm{Y}-\mathrm{H} 2 \mathrm{AX}$

Merge

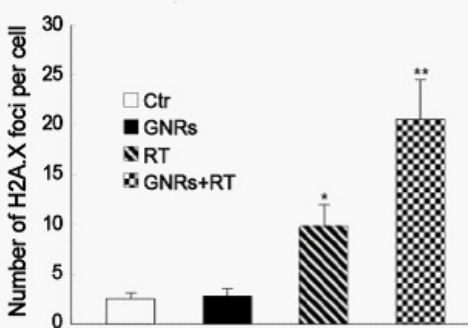

Fig. 4 Quantitative analysis of radiation-induced $\gamma$-H2AX foci. The A375 cells were incubated with GNRs $(50 \mu \mathrm{g} / \mathrm{ml})$ for $1 \mathrm{~h}$ prior to irradiation with $6 \mathrm{MV}$ X-rays with a dose of $2 \mathrm{~Gy}$. The cells were fixed at $1 \mathrm{~h}$ after the irradiation and stained with the flourescein isothiocyanate ( FITC)-labeled mouse monoclonal antibody against $\gamma$-H2A.X and DAPI for analysis of the nuclear $\gamma-\mathrm{H} 2 \mathrm{AX}$ foci by fluorescent microscope. A: the immunofluorescence images of the nuclear $\gamma$-H2AX foci . B: quantitative analysis of the nuclear $\gamma$-H2AX foci in the cells with different treatments. Columns, mean from three repeated experiments; bars, SD. ${ }^{*} \mathrm{p}<0.05$ compared to control group; $* * \mathrm{p}<0.05$ compared to RT group. 


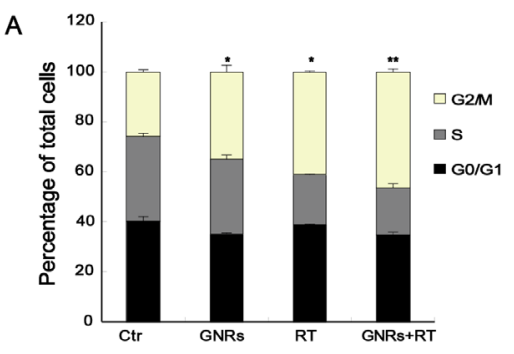

B

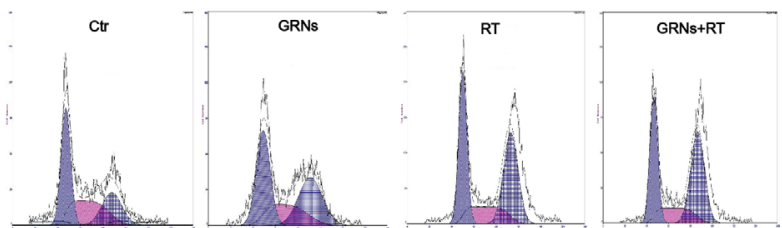

Fig. 6 GNRs induce cell -cycle arrest in the $G_{2} / M$ phase of the cell cycle. The A375 cells were incubated with GNRs $\left(50 \mu \mathrm{g} \mathrm{mL}^{-1}\right)$ for $1 \mathrm{~h}$, then the cells were stained with propidium iodide, and analyzed by flow cytometry $24 \mathrm{~h}$ after radiation. Experiments were done in triplicates. Columns, mean from three repeated experiments; bars, SD. A: the percetage of different cell phase. B: histogram of flow cytometry. (abbreviation: Ctr: control)

GNRs may have the potential to be used for biologically targeted imaging and therapy. Our results showed that radioresistant melanoma cells treated with GNRs could synergistically enhance the cytotoxicities of radiation in terms of apoptosis and mitotic death (Fig. 5), about three fold enhancement of radiosensitivity was achieved compared to radiation alone. The mechanisms whereby GNRs enhanced the response to radiation were associated with multiple factors.

It is believed that the role of the cell cycle phase is critical to the response of cancer cells to radiation, GNRs or radiation alone resulted in an increase in the percentage of cells in the $\mathrm{G}_{2} / \mathrm{M}$ phase of the cell cycle , and this effect was enhanced when the two treatments were combined (Fig. 6). Because tumor cells are more radiosensitive in the $\mathrm{G}_{2} / \mathrm{M}$ phase compared to the $\mathrm{G}_{0} / \mathrm{G}_{1}$ or $\mathrm{S}$ phase [24], increased radiation-induced cytotoxicities were seen following the cell being treated with a combination of GNRs and radiation in terms of apoptosis and mitotic death. Likewise, increased cell numbers in the $G_{2} / M$ phase could also explain some of the increase in susceptibility to radiation-induced DNA damage reflected by the increased expression of $\gamma \mathrm{H} 2 \mathrm{AX}$, compared to cells treated with radiation alone [25]. Our data showed that melanoma cells treated by GNRs plus radiation had more $\gamma \mathrm{H} 2 \mathrm{AX}$ foci compared to radiation alone (Fig. 4). Based on these findings, the disruption of the cell cycle phases by GNRs might determine the relative radiosensitivity of A375 cells.

Another possible mechanism for GNRs-mediated radiosensitization is that GNRs enhance radiationinduced DNA damage in the cells. It is well established that the primary focus of radiation damage is nuclear DNA, with DSB formation is the most lethal lesion to the DNA. $\gamma-\mathrm{H} 2 \mathrm{AX}$ expression has been shown as a sensitive indicator of DSBs induced by clinically relevant doses of ionizing radiation [26]. At sites of radiation-induced
DNA DSBs, the histone H2AX becomes phosphorylated rapidly $(\gamma-\mathrm{H} 2 \mathrm{AX})$, forming nuclear foci that can be visualized by immunofluorescence microscopy [27]. Although the specific role of $\gamma-\mathrm{H} 2 \mathrm{AX}$ in the repair of DSBs has not been defined, recent reports indicate the dephosphorylation of $\gamma-\mathrm{H} 2 \mathrm{AX}$ and dispersal of $\gamma-\mathrm{H} 2 \mathrm{AX}$ foci in irradiated cells correlates with the repair of DNA DSBs and cellular radiosensitivity [28, 29]. Our data showed in Fig 4 that melanoma cells treated by GNRs plus radiation had two fold higher of the average number of $\gamma-\mathrm{H} 2 \mathrm{~A}$.X foci per cell than radiation alone $(20.6 \pm 3.9$ Vs 9.8 \pm 2.2 ), the quantitation of DSBs using $\gamma-\mathrm{H} 2 \mathrm{~A} . \mathrm{X}$ foci was consistent with GNRs-mediated radiosensitization in terms of apoptosis and mitotic death.

Since GNRs have the interesting properties such as increasing the absorption of radiation energy and their preferential accumulation in cancer cells [29-32]. It has long been realized that the effect of a defined dosage is increased when a high- $Z$ material is in the targeted zone through a photoelectric effect [33], and the enhancement is proportional to the amount of the high- $Z$ material. This explained why GNRs, which have high atomic number (Z), preferentially absorb kilovoltage x-rays. The radiosensitizing effect of MV x-rays cannot be attributed to high- $Z$ materials alone. The possible mechanism is that GNRs to enhance the cytotoxicities of MV x-rays, when irradiated in the cell, produce a high level of intracellular reactive oxygen species (ROS), which leads to elevated levels of oxidative stress and is manifested as an increased level of apoptosis compared to irradiation alone [34]. An additional hypothesis proposed on the basis of DNA plasmid models, suggested that sensitization occurs due to short-range electrons produced by the interaction between GNRs and MV X-rays [25]. The increased production of low-energy electrons close to the DNA causes more damage than radiation alone. Our data confirmed that GNRs plus radiation induced more apoptosis and mitotic death in A375 cells than radiation alone.

In summary, we demonstrated that GNRs have remarkable potential to enhance radiotherapy of melanoma cancer cells. GNRs, in combination with $6 \mathrm{MV}$ irradiation, enhance the radiosensitivity of the cells. This radiosensitizing effect may be attributable to alterations of cell's capacity to resist apoptosis caused by the GNRs, mainly through enhancement of radiationinduced DSBs and arresting the cell cycle at the $\mathrm{G}_{2} / \mathrm{M}$ phase. As the success of radiotherapy for patients with melanoma largely depends on tumor radiosensitivity, the combination of GNRs and radiation needs further investigation.

\section{Acknowledgements}

This article was funded by research grants (Grant No.09JC411900, 09411951100, 08411960600) from the Science and Technology Commission of Shanghai, and National Nation Science Foundation of China (81171377), National Basic Research Program of China [No.2011CB707504, No.2010CB933903], People's Republic of China. 
The authors thank Dr. T. FitzGibbon for comments on earlier drafts of the manuscript

\section{References}

1. Ferlay J. Age-standarised incidence rates from the GLOBOCAN 2008 database (http://www-dep.iarc.fr/) using World 2000 population as standard provided on request. 2010.

2. Zygogianni A, Kyrgias G, Kouvaris J, et al. Melanoma: the radiotherapeutic point of view; review of the current literature. Rev Recent Clin Trials. 2011; 6(2): 127-33.http://dx.doi. org/10.2174/157488711795177877

3. Ristic-Fira AM, Todorovic DV, Koricanac LB, et al. Response of a human melanoma cell line to low and high ionizing radiation. Ann N Y Acad Sci. 2007; 1095:165-74. http://dx.doi.org/10.1196/ annals.1397.020

4. Pak BJ, Lee J, Thai BL, et al. Radiation resistance of human melanoma analysed by retroviral insertional mutagenesis reveals a possible role for dopachrome tautomerase. Oncogene. 2004; 23(1): 30-38. http://dx.doi.org/10.1038/sj.onc.1207007

5. Kong T, Zeng J, Wang X, et al. Enhancement of radiation cytotoxicity in breast-cancer cells by localized attachment of gold nanoparticles. Small. 2008; 4(9): 1537-1543.http://dx.doi. org/10.1002/smll.200700794

6. Hainfeld JF, Slatkin DN, Smilowitz HM. The use of gold nanoparticles to enhance radiotherapy in mice. Phys Med Biol. 2004; 49 (18): N309-N315.http://dx.doi.org/10.1088/0031-9155/49/18/N03

7. Unezaki S, Maruyama K, Hosoda J-I, et al. Direct measuremen of the extravasation of polyethyleneglycol-coated liposomes into solid tumour tissue by in vivo fluorescence microscopy. Int J Pharm. 1996; 144(1): 11-17. doi: org/10.1016/S0378-5173(96)04674-1

8. Iyer AK, Khaled G, Fang J, Maeda H. Exploiting the enhanced permeability and retention effect for tumor targeting. Drug Discovery Today. 2006; 11(17-18): 812-818. doi: org/10.1016/ j.drudis.2006.07.00

9. Spiers $F W$. The influence of energy absorption and electron range on dosage in irradiated bone. Br J Radiol. 1949; 22(261): 521-533. http://dx.doi.org/10.1259/0007-1285-22-261-521

10. Chen W, Zhang J. Using nanoparticles to enable simultaneous radiation and photodynamic therapies for cancer treatment. $J$ Nanosci Nanotechnol. 2006; 6(4): 1159-1166. doi: org/10.1166/ jnn.2006.327

11. Robar JL, Riccio SA, Martin MA. Tumour dose enhancement using modified megavoltage photon beams and contrast media. Phys. Med. Biol. 2002; 47(14): 2433-2449.http://dx.doi. org/10.1088/0031-9155/47/14/305

12. Tiwari PM, Vig K, Dennis VA, Singh SR. Functionalized Gold Nanoparticles and Their Biomedical Applications. Nanomaterials. 2011; 1(1): 31-63. doi: 10.3390/nano10100 31

13. Chen SH, Ji YX, Lian Q, et al. Gold Nanorods Coated with Multilayer Polyelectrolyte as Intracellular delivery Vector of Antisense Oligonucleotides. Nano Biomedicine and Engineering. 2010; 2(1): 15-23.http://dx.doi.org/10.5101/nbe.v2i1.p15-23

14. Zhang XQ, Pan BF, Wang K, et al. Electrochemical Property and Cell Toxicity of Gold Electrode Modified by Monolayer PAMAM Encapsulated Gold Nanorods. Nano Biomedicine and Engineering. 2010; 2(3): 182-188.http://dx.doi.org/10.5101/nbe.v2i3.p182-188

15. Pan B, Ao L, Gao F, et al. End-to-end self-assembly and colorimetric characterization of gold nanorods and nanospheres via oligonucleotide hybridization. Nanotechnology. 2005; 16(9): 17761780. http://dx.doi.org/10.1088/0957-4484/16/9/061

16. Murphy C, Jana N. Controlling the aspect ratio of inorganic nanorods and nanowires. Adv. Mater. 2002; 14(1): 80-82.http:// dx.doi.org/10.1002/1521-4095(20020104)

17. Li X, Kao FJ, Chuang CC, He S. Enhancing fluorescence of quantum dots by silica-coated gold nanorods under one- and two-photon excitation. Opt Express. 2010; 18(11): 11335-11346. doi:org/10.1364/OE.18.011335

18. Chithrani DB, Jelveh S, Jalali F, et al. Gold Nanoparticles as Radiation Sensitizers in Cancer Therapy. Radiation Research. 2010; 173(6): 719-728.doi: 10.1667/RR1984.1http://dx.doi.org/10.1667/ RR1984.1

19. Lechtman E, Chattopadhyay N, Cai Z, et al. Implications on clinical scenario of gold nanoparticle radiosensitization in regards to photon energy, nanoparticle size, concentration and location. Phys Med Biol. 2011; 56(15): 4631- 4647. http://dx.doi.org/10.1088/0031$9155 / 56 / 15 / 001$

20.Tallury P, Payton K, Santra S. Silica-based multimodal/ multifunctional nanoparticles for bioimaging and biosensing applications. Nanomedicine. 2008; 3(4): 579-592. http://dx.doi. org/10.2217/17435889.3.4.579

21. Zhan Q, Qian J, li Xin, et al. A study of mesoporous silicaencapsulated gold nanorods as enhanced light scattering probes for cancer cell imaging. Nanotechnology. 2010; 5(21): 055704. http://dx.doi.org/10.1088/0957-4484/21/5/055704

22. Chattopadhyay N, Cai ZL, Pignol JP, et al. Design and characterization of HER-2-targeted gold nanoparticles for enhanced X-radiation treatment of locally advanced breast cancer. Molecular Pharmaceutics. 2010; 7(6): 2194-2206. http://dx.doi.org/10.1021/ mp100207t

23. Kumar A, Ma H, Zhang X, et al. Gold nanoparticles functionalized with therapeutic and targeted peptides for cancer treatment. Biomaterials. 2012; 33(4): 1180-1189. http://dx.doi.org/10.1016/ j.biomaterials.2011.10.058

24. Sinclair WK. Cyclic $\mathrm{x}$-ray responses in mammalian cells in vitro. Radiat Res. 1968; 33(3): 620-643. http://dx.doi.org/10.2307/3572419

25. Zheng Y, Hunting DJ, Ayotte P, Sanche L. Radiosensitization of DNA by gold nanoparticles irradiated with high-energy electrons. Radiat Res. 2008; 169(1): 19-27.http://dx.doi.org/10.1667/RR1080.1

26. Löbrich M, Shibata A, Beucher A, et al. $\gamma \mathrm{H} 2 \mathrm{AX}$ foci analysis for monitoring DNA double-strand break repair: Strengths, limitations and optimization. Cell Cycle. 2010; 9(4): 662-669. http://dx.doi. org/10.4161/cc.9.4.10764

27. Sedelnikova OA, Rogakou EP, Panyutin IG, et al. Quantitative detection of (125) IdU-induced DNA double-strand breaks with $\gamma$-H2AX antibody. Radiat Res. 2002; 158(4): 486-492.http://dx.doi. org/10.1667/0033-7587(2002)158[0486:QDOIID]2.0.CO;2

28. Taneja N, Davis M, Choy JS, et al. Histone H2AX phosphorylation as a predictor of radiosensitivity and target for radiotherapy. $J$ Biol Chem. 2004; 279(3): 2273-2280.http://dx.doi.org/10.1074/jbc. M310030200

29. MacPhail SH, Banath JP, Yu TY, et al. Expression of phosphorylated histone $\mathrm{H} 2 \mathrm{AX}$ in cultured cell lines following exposure to X-rays. Int J Radiat Biol. 2003; 79(5): 351-358. http://dx.doi. org/10.1080/0955300032000093128

30. Chen Wand, Zhang J. Using nanoparticles to enable simultaneous radiation and photodynamic therapies for cancer treatment. $J$ Nanosci Nanotechnol. 2006; 6(4): 1159-1166.http://dx.doi. org/10.1166/jnn.2006.327

31. Huang P, Bao L, Zhang CL, Lin J, Luo T, Yang DP, et al. Folic acidconjugated Silica-modified gold nanorods for X-ray/CT imagingguided dual-mode radiation and photo-thermal therapy. Biomaterials 2011; 32: 9796-9809.http://dx.doi.org/10.1016/j.biomaterials. 2011.08.086

32.Zhang CL, Huang P, Bao L, He M, Luo T, Gao G, et al. Enhancement of Gastric Cell Radiation Sensitivity by ChitosanModified Gold Nanoparticles. Journal of Nanoscience and Nanotechnology 2011;11(S1): 9528-9535 http://dx.doi. org/10.1166/jnn.2011.5318

33. Spiers FW. The influence of energy absorption and electron range on dosage in irradiated zone. Br J Radiol. 1949; 22(261): 521-533. http://dx.doi.org/10.1259/0007-1285-22-261-521

34. Geng F, Song K, Xing JZ, et al. Thio-glucose bound gold nanoparticles enhance radio-cytotoxic targeting of ovarian cancer. Nanotechnology. 2011; 22(28): 285101 (8pp). doi:10.1088/0957$4484 / 22 / 28 / 28510$

Copyright:(c) 2012 W. Xu, et al. This is an open-access article distributed under the terms of the Creative Commons Attribution License, which permits unrestricted use, distribution, and reproduction in any medium, provided the original author and source are credited. 